\title{
A Retrospective Study of Intestinal Obstruction and Anastomotic Leak in Emergency and Sepsis Cases
}

\author{
Chandu Sambasivudu ${ }^{1}$, Chandu Vineela ${ }^{2}$ \\ ${ }^{1}$ Department of General Surgery, Sri Venkateswara Nursing Home, Tenali, NRI Medical College, \\ Guntur, Andhra Pradesh, India. ${ }^{2}$ Department of General Medicine, Sri Venkateswara Nursing \\ Home, Tenali, NRI Medical College, Guntur, Andhra Pradesh, India.
}

\section{ABSTRACT}

\section{BACKGROUND}

Intestinal obstruction is one of the most common intra-abdominal problems dealt by general surgeons. The morbidity and mortality are much higher than many diseases. If diagnosed \& treated early, the recovery time, morbidity \& mortality are much less. Hence the need for the study.

\section{METHODS}

We have analysed 216 cases of intestinal obstruction done by a single surgeon in one hospital in the last three decades. Differences in the selection, surgical skill, capability, $\&$ post-operative care management are excluded by including a single surgeon's $\left(1^{\text {st }}\right.$ Author) operated cases. Only operated cases are included in the study. Conservatively managed patients are not included in this study.

\section{RESULTS}

Females are more affected 56\%, than $44 \%$ males. If Pelvic pathology cases are excluded - both sexes are equally affected. Small intestine was affected in $88 \%$ of patients. Anastomotic leak occurred in 8 patients (3.7\%). Burst abdomen occurred in 4 patients $-1.85 \%$. Re-exploration was done in 13 patients $(6.0 \%)$. LAMA \& death together accounted for 6 cases (2.8\%). Success rate of all operations was $97.2 \%$.

\section{CONCLUSIONS}

Female sex is more commonly effected. Adhesion \& bands are major causes of small bowel obstruction. Anastomotic leak is common in strangulated bowels with associated with septic shock. PGA (Vicryl) \& PDS are better than catgut in decreasing the leak rate. Mortality rate is more in anastomotic leak patients.

\section{KEY WORDS}

Intestinal Obstruction, Small Bowel, Ileum, Jejunum, Appendix, Colon, Hernia Volvulus, Anastomosis, Colostomy, Adhesions, Anastomotic Leak

\author{
Corresponding Author: \\ Dr. Chandu Sambasivudu, \\ D. No. 22-7-21, \\ SVN Home, Kothapeta, \\ Tenali-522201, Guntur, Dist., \\ Andhra Pradesh, India. \\ E-mail: dr.ch.sivudu@gmail.com
}

DOI: $10.14260 / \mathrm{jemds} / 2020 / 462$

How to Cite This Article:

Sambasivudu C, Vineela C. A retrospective study of intestinal obstruction and anastomotic leak in emergency and sepsis cases. J. Evolution Med. Dent. Sci. 2020;9(30):2119-2123, DOI: $10.14260 /$ jemds/2020/462

Submission 21-04-2020,

Peer Review 13-06-2020,

Acceptance 22-06-2020,

Published 27-07-2020.

Copyright (c) 2020 JEMDS. This is an open access article distributed under Creative Commons Attribution License [Attribution 4.0 International (CC BY 4.0)] 


\section{BACKGROUND}

Intestinal obstruction is defined as a condition "when normal propulsion \& passage of intestinal contents cannot occur for any reason. This can involve small bowel or large bowel or via systemic alteration in metabolism, electrolyte balance, or neuro-regulatory mechanism involving the bowel ${ }^{1}$.

Hippocrates the father of medicine recognized, described \& treated bowel obstruction. Praxa Goras done earlier recorded operation for bowel obstruction. Circa in $350 \mathrm{BC}$ treated bowel obstruction by decompression i.e. Enterocutaneous fistula. ${ }^{1}$

Intestinal obstruction may be due to

1. Mechanical (Physical) obstruction or dynamic obstruction,

2. Adylamic or functional obstruction, it is ineffective motility without any mechanical obstruction - paralytic ileus.

Mechanical obstruction is the most common \& for all practical purposes it is synonymous with intestinal obstructions in this study. We are dealing with mechanical obstruction only. $15 \%$ of hospital admissions for pain abdomen are due to intestinal obstruction. ${ }^{2}$ In first third of the $20^{\text {th }}$ century Intestinal obstruction is mainly due to inguinal hernial obstruction. In the $2^{\text {nd }}$ half the $20^{\text {th }}$ the century adhesions \& bands are common causes due to a greater number of abdominal surgeries. Now in $21^{\text {st }}$ century pelvic pathology adhesions involving uterus \& adnexa to intestines are seen more commonly than before ${ }^{3}$ due to high incidence of caesarean section for delivery (LSCS).

Intestinal obstruction is most commonly encountered disease in the surgical emergency OPD. $1 \%$ of all hospitalizations \& $3 \%$ of all surgical admissions $\& 4 \%$ all major laparotomies are due to intestinal obstruction ${ }^{4}$. It is simple surgery if obstruction is due to simple adhesion or band without any bowel damage. It is highly complicated if bowel is gangrenous due to vascular impairment either due to large volvulus or strangulated hernia or plastered intestines in long standing peritonitis. It carries high mortality of $10-37 \% 5$. Hypotension \& septic shock - which leads to multi organ failure and death. We have done all intestinal anastomosis with hand sewn sutures \& all are open surgeries only.

\section{Objectives}

1. To know the various causes of intestinal obstructions \& its morbidity \& mortality specially so in strangulated \& long-standing obstruction due to intestinal perforation \& sepsis.

2. To decrease the anastomotic leak \& there by decreasing the morbidity \& mortality.

\section{METHODS}

We have studied 216 cases of intestinal obstruction retrospectively operated by single surgeon (1 1 st author). Both small \& large bowel obstruction cases of all causes are included in this study. Conservatively managed intestinal obstruction cases are not included - due to lack of definitive

\begin{tabular}{|ccccc|}
\hline Age (Years) & Male & Female & Total & Percentage \\
$0-20$ & 14 & 14 & 28 & $13.0 \%$ \\
$21-40$ & 34 & 48 & 82 & $37.96 \%$ \\
$41-60$ & 29 & 44 & 73 & $33.79 \%$ \\
$61-80$ & 16 & 14 & 30 & $13.76 \%$ \\
$>80$ & 02 & 01 & 03 & $1.38 \%$ \\
Total & $\mathbf{9 5}$ & $\mathbf{1 2 1}$ & $\mathbf{2 1 6}$ & $\mathbf{1 0 0} \%$ \\
Percentage & $\mathbf{4 4 \%}$ & $\mathbf{5 6} \%$ & & \\
\hline
\end{tabular}

Table 1. Age \& Sex Wise Distribution of Cases of Intestinal Obstruction

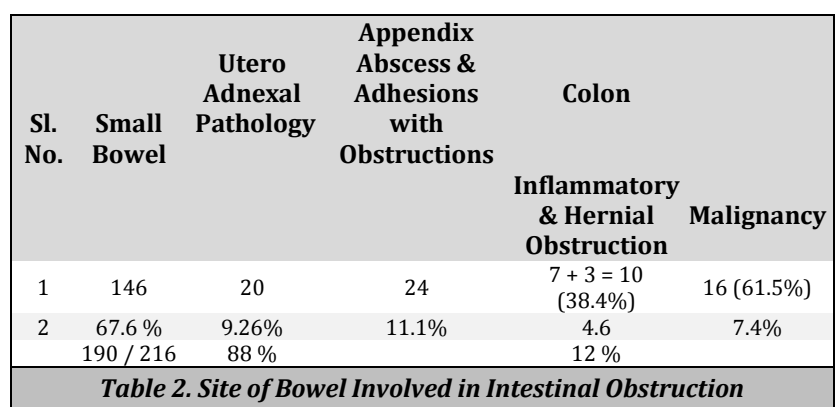

\begin{tabular}{|c|c|c|c|c|}
\hline $\begin{array}{l}\text { Sl. } \\
\text { No. }\end{array}$ & $\begin{array}{l}\text { Cause of the } \\
\text { Obstruction }\end{array}$ & No. of Cases & $\%$ & $\begin{array}{l}\text { Nature of the } \\
\text { Lesion } \%\end{array}$ \\
\hline 1 & Adhesions only & 57 & $26.4 \%$ & Pure Adhesions \\
\hline 2 & Pelvic adhesions, + post LSCS & 20 & $9.26 \%$ & $42.66 \%$ \\
\hline 3 & bands & 15 & $7.0 \%$ & \\
\hline 4 & $\begin{array}{l}\text { Appendicular abscess \& } \\
\text { + mass with intestinal } \\
\text { obstructed }\end{array}$ & $10+14=24$ & $11.1 \%$ & $11.1 \%$ \\
\hline 5 & $\begin{array}{c}\text { Inguinal hernia with } \\
\text { obstructed, + strangulated }\end{array}$ & $12+3=15$ & $6.9 \%$ & Hernias $16.7 \%$ \\
\hline 6 & $\begin{array}{c}\text { Femoral hernia - obstructed, } \\
\text { strangulated }\end{array}$ & $1+2=3$ & $1.4 \%$ & \\
\hline 7 & $\begin{array}{l}\text { Incisional hernia, + other } \\
\text { ventral hernias, (obst., } \\
\text { + strangulated) }\end{array}$ & $14+4=18$ & $8.3 \%$ & \\
\hline 8 & $\begin{array}{l}\text { Volvulus, small bowel, + } \\
\text { sigmoid colon }\end{array}$ & $\begin{array}{c}8+4+12, \\
\text { 4 Non-Gangrenous, } \\
+8 \text { Gangrenous }\end{array}$ & $5.6 \%$ & $5.6 \%$ \\
\hline 9 & $\begin{array}{l}\text { Meckel's diverticulum of } \\
\text { ilium }\end{array}$ & 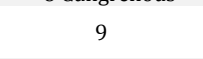 & $4.2 \%$ & \\
\hline 10 & Malignancy & $16+5=21$ & 9.7 & $9.7 \%$ \\
\hline 11 & Tuberculosis of abdomen & 4 & $1.85 \%$ & \\
\hline 12 & $\begin{array}{l}\text { Ischemic causes acute } \\
\text { segmental enteritis }+ \\
\text { mesenteric vascular }\end{array}$ & $3+1=4$ & $1.85 \%$ & \\
\hline 13 & Post radiation adhesion & 4 & $1.85 \%$ & \\
\hline 14 & Urachal cyst with obstruction & 3 & $1.4 \%$ & \\
\hline 15 & Intussusception & 2 & $0.93 \%$ & \\
\hline 16 & $\begin{array}{l}\text { Other causes, primary } \\
\text { peritonitis etc... }\end{array}$ & 5 & $2.3 \%$ & \\
\hline & Total & 216 & $100 \%$ & \\
\hline \multicolumn{5}{|c|}{ Table 3. Causes of Intestinal Obstruction in Detail } \\
\hline
\end{tabular}

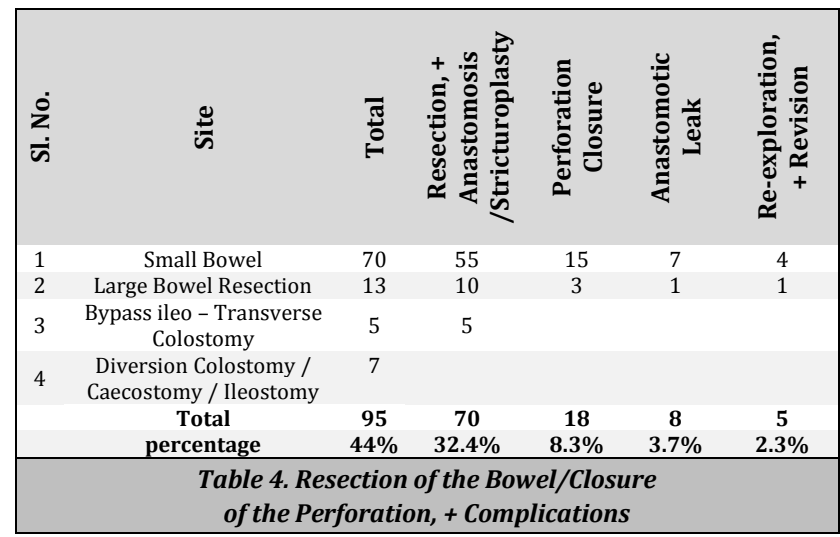

aetiology confirmation. Trauma either blunt or stab wound cases producing hemoperitoneum/Ectopic pregnancy rupture cases are also not included. Supra meso colic perforations like gastric perforation, DU perforation are not included in this study. Simple appendicitis/gangrene/perforation or minimal adhesions are not taken into this study. Only appendicular abscess or appendicular mass with considerable adhesions 
producing distension of the small bowel\& acute small bowel obstruction only are included in this study. Immediate postoperative adhesion obstructions after LSCS cases within 2 weeks are included-(5) cases. Ruptures of the ovarian tumour /cyst with adhesions to the uterus \& intestines producing intestinal obstructions are included in this study- (15). Subacute intestinal obstruction of colonic malignancy, tuberculosis, perforations of small bowel \& colon producing intestinal distension, adhesions are all included in this study.

All of them are operated under spinal/general anaesthesia. Many patients of strangulated bowel with hypotension are treated with inotropes like dopamine 5-20 micro grams/Kg/Minute. doses for 1-5 days preoperatively \& post operatively till recovery. Acute renal failure is also treated accordingly. Anastomosis /closure of perforation of small bowel done with 2-0 chromic catgut and 2 - 0 silk in two layers before 2005. After 2005 all anastomoses were done with 2 0/3-0 PGA (Vicryl) \& silk (Continuous). Colocolic anastomosis was done with 2-0 PGA (Vicryl) interrupted single layer /Double layers.

All are open surgeries \& hand sewn anastomosis only. It is less costly. When signs of anastomotic leak occurred generally in $5-7^{\text {th }}$ post-operative day - reexplored in 5/8 cases \& reanastomosis/diversion procedures were done basing on the condition of the patient. The curative surgery was done in all cases depending on their aetiology namely, adhesiolysis, band release, herniotomy + repair, appendicectomy + drainage abscess, resection of strangulated bowel, closure of the perforation of the bowel, diversion, de functioning procedures were done accordingly. Management wise analysis - bowel resection / perforation closure is shown in table 4.

\section{Complications}

\section{Immediate Post-Operative Complications}

1. Recovery from Anaesthesia- Not recovered well in 3 people, hence ventilated per 1 - 2 days -recovered well.

2. Septic Shock- Hypotension and septic shock within 6-12 hrs., of the surgery in 20 patients who were treated with dopamine drip 5 - 20 micro grams per KG per minute dose till they recover from the condition, IV Fluids, antibiotics \& steroids if necessary.

3. Burst Abdomen- 5 - 7 days post-operative period - 4 cases, burst repaired under anaesthesia recovered \& discharged well.

4. Post-Operative Obstruction- 4-6 postop day-4 cases, reexplored adhesiolysis + peritoneal lavage done recovered well \& discharged.

5. Re-exploration in Anastomotic Leak- 5 cases, Total - 13 Re-explorations.

\section{Total Anastomotic Leak - 8}

3 people were not willing to re-exploration. Post radiation badly plastered intestines (1), mesenteric vascular Ischemia (1), 7 days old peritonitis following hysterectomy injuring ileum outside- $1 / 3$ They got discharged against medical advice (LAMA). Treated as deaths in our study. 2 cases of ileal resection had leak and reexplored - not recovered peristalsis (? Neuro- Regulatory). 3 days old strangulated inguinal hernia resection ileal leak - reexplored \& revision anastomosis done septic shock. Above 3 patients had multi organ failure and died in hospital. Sigmoid colon resection and primary colorectal anastomosis had leak - diversion colostomy done - recovered well. Post radiation resection anastomosis leak reexplored \& sutured + peritoneal lavage recovered well.

\section{Wound Infection}

Superficial wound infections: in 15 cases $-6.9 \%$ - PUS drained - and dressings done regularly - recovered in 7 - 10 days post operatively.

\section{RESULTS}

Females are affected are more $-56 \% .21$ - 40 yrs. people are affected $38 \%$. Small bowel obstruction is more common $88 \%$. Colon is involved in $12 \%$. Pure adhesions \& bands constitutes 42.66\%. Inflammatory pathology (appendicular)11.1\%, Hernia is cause of the obstruction $16.7 \%$ malignant obstructions are $9.7 \%$ \& volvulus in $5.6 \%$ \& other causes are in $14.38 \%$. Septic shock in $9.26 \%$, Burst abdomen in $1.9 \%$. Resection+ EEA+ BYPASS anastomosis $32.4 \%$, re-exploration in $6 \%$ of cases, Anastomotic leak rate $11 \%$, mortality rate $2.8 \%$, success rate $97.2 \%$.

\section{Serious Cases}

If we take strangulated/perforated/gangrenes/malignant cases $6 / 88$ - we have the death rate of $6.82-7 \%$. Hospital stay: 8 - 14 days.

\section{DISCUSSION}

Female sex is more involved due to pelvic organ adhesions producing intestinal obstruction. The same is true with other series of India \& Abroad. ${ }^{6}$ Small bowel is involved in $88 \%$. Colon is involved in $12 \%$ of cases in our series-Out of them. Malignancy constitutes $61.5 \% \&$ inflammatory \& obstruction due to hernia causes- $38.5 \%$. Haribhakti et al, quoted in their surgical gastroenterology book - $80 \%$ of intestinal obstruction is due to small bowel, $20 \%$ is due to large bowel. Out of large bowel lesions - colorectal malignancy is $60-70 \%$ \& other causes $30-40 \%$. From Western country series quotes $80-$ $90 \%$ are small bowel obstructions \& large bowel constitutes $10-20 \%$. Out of large bowel lesions $60-70 \%$ are malignancy, $30-40 \%$ are due to volvulus, diverticulitis and Chron's. Our series incidence is reasonably consistent with the above studies.

In our study Adhesions, bands \& gynaecological causes are more common $-42.66 \%$. Appendicular causes are in $11.1 \%$ \& hernia causes are - $16.7 \%$. Malignancy is $9.7 \%$ in cases, Volvulus is $5.6 \%$. Ischemic causes $1.85 \%$, Post radiation 1.85 $\%$. According to textbook of surgery Bailey \& Love'sAdhesions constitute $40 \%$, Hernias - 12\%, Inflammatory - 15 
$\%$, Carcinoma-15\%, Faecal impaction - 8\%, Pseudo obstruction $-5 \%$ \& other causes are $5 \% .^{7}$

We have not operated any faecal impaction case. We have relieved the obstruction by manual evacuation. Hence, we have not included in our study. Pseudo obstructions (? Adynamic) are not included in our study. Malignant causes are less in our study - might be due to small center \& single surgeon series.

Miller $\mathrm{G}$ et al quoted in their series colorectal surgery causes-24\%, adhesions, gynaecology surgery 22\%, herniorrhaphy $15 \%$ \& Appendicectomy $14 \% .{ }^{8}$

Foster NM et al in their prospective study of longitudinal and population-based analysis of SBO -Adhesions are 38\%, Hernia repair $38 \%$, Small bowel resection $-18 \%$ are the causes of the obstructions. ${ }^{9}$

Our study reports are not much variant of the above studies. Due to late presentation of appendicular causes, Enteric perforations with obstructions, increased incidence of incisional hernia obstruction, strangulation\& Increased LSCS rates might be responsible for the differences.

We have $5.6 \%$ of both small bowel \& sigmoid colon volvulus. Among the volvulus small bowel constitutes $67 \%$ (3.7\% of all cases) \& Sigmoid volvulus $33 \%-(1.85 \%$ of all cases). Out of them $67 \%$ strangulated. In the Bolivian and Peruvian Andes, high altitudes of 10,000 feet and above will have more, commonly affected with sigmoid volvulus $79 \%$. But other series quotes $1-4 \%$ of sigmoid volvulus of all intestinal obstructions. ${ }^{10}$

Ischemic causes - We have 4 patients of intestinal ischemia. 3 cases are patchy or segmental gangrenous small bowel with mesenteric arcade thrombosis. One case of frank large segment small bowel ischemic gangrene due to medium sized artery thrombosis. Acute segmental necrotizing enteritis is seasonal disease as reported by Pujari et al ${ }^{11} \&$ J. D. WIG et al. ${ }^{12}$ Mesenteric vascular ischemic lesions of the bowel caries high mortality according to Schoot's et al. ${ }^{13}$ Which is same in our study also.

We had only $0.9 \%$ of intussusception cases responsible for intestinal obstruction. It is less than other series of $2 \%{ }^{14}$

Intestinal tuberculosis is not rare in earlier days but now it is decreased due to widespread use of Anti tuberculosis treatment (ATT). We had 2 cases of intestinal strictures where Stricturoplasty ${ }^{15}$ was done $\& 2$ cases of peritoneal tuberculosis treated with ATT.

We have not encountered either diverticulitis/Chron's disease producing intestinal obstruction in this place.

We have 4 cases of post radiation intestinal obstruction due to mainly small bowel adhesions \& plastered coils to each other. They are very much difficult to lyse or separation, hence we have done Bypass/defunctioning procedure. Due to increased longevity of post malignant therapy - these cases are increasing.

We have done 70 resections of both small bowel \& large bowel and end to end anastomosis of bowel or ileotransverses colostomy. All are hand sewn anastomosis mostly double layer continuous PGA (Vicryl) suture. Left colic anastomosis were done with interrupted single- or double-layer sutures. Majority of the cases are strangulated/gangrenous bowel due to volvulus/strangulated inguinal, incisional hernias/Peritonitis with necrotic bowel. Nearly $10 \%$ of all cases or $28.6 \%$ resection cases were associated with septic shock. $1.85 \%$ resections are in post radiation cases.
We had anastomotic leak of $11 \%$ in resection cases out of them $6.8 \%$ resections had Left against Medical advice or death in hospital.

For any bowel anastomosis to heal well, the following 16 criteria are necessary-

1. Well-nourished patients.

2. Good vascularity of tissue of both ends of bowel.

3. Clean bowel-No luminal or extra luminal contamination.

4. No tension on anastomosis.

5. Meticulous surgical technique - Good opposition \& inversion of mucosa.

6. Good exposure.

7. Monofilament\& coated suture material which invites Lesser inflammatory reaction \& durability.

Factors which delay ${ }^{17}$ healing are

1. Septic shock - hypotension - Decreased vascular supply to the anastomosis.

2. Post radiation, which causes micro vascular damage decreases vascular supply to the anastomosis.

3. Anaemia \&Diabetes

4. Chemotherapy

5. Malnutrition \& hypo albuminemia.

6. Vitamin deficiency

7. Jaundice \& Uraemia.

Various authors reported anastomotic leak rates ranging from $5-28 \%$ in elective cases. Singh et al reported anastomotic leak rate of $5-9 \% .{ }^{18}$ Metthiessen et al reported over all anastomotic leak rate of $19.2 \%$ without diversion stoma 28 $\% .{ }^{19}$ Fielding et al reported anastomotic leak rate of $13 \%$ Anastomotic Leak rate is less in small bowel due to less extensive collagen loss \& restored more rapidly. Small bowel is also more vascular ${ }^{21}$. Burch MM et al reported almost equal anastomotic leak rate in single layer or double layer anastomosis. ${ }^{22} \mathrm{G}$ Docherty found not much difference between stapled verses hand sewn anastomosis in clinical anastomotic leak, morbidity and mortality rates ${ }^{23}$. Stapled anastomosis is technically problematic, more costly and more post-operative strictures. Our anastomotic leak rate of $11 \%$ in emergency and toxic conditions are within the range of acceptability.

We had re-explorations in $6 \%$ of cases due to

1. Anastomotic leak

2. Burst abdomen.

3. Post-operative adhesions - altogether.

Elloz et al reported reexploration rate of $13 \%^{24}$ Metthiessen et al reported urgent reexploration rate of $25.4 \%$ in patients without diversion stoma.

\section{Mortality Rate}

We had $2.8 \%$ mortality rate out of all intestinal obstruction or $6.8 \%$ of all strangulated and perforation cases. Various series quotes mortality rate of $10-37 \% \%^{5}$. Our mortality rate is less due to 1 . Early diagnosis 2. Careful observations 3. Prompt \&needed surgery 4. Post-operative care by senior surgeon. We have operated all acute small bowel obstructions - who fail to improve after $48 \mathrm{hrs}$., of conservative treatment. The same is advocated by Sosa J et al. ${ }^{25} \mathrm{We}$ are not in agreement of Sajja et 
al who advocated 10-14 days of conservative treatment ${ }^{26}$ which is more costly - caries high morbidity and mortality.

Sarr MG et al reported that in prospective evaluation of pre -operative judgement is difficult to predict the ischemia/ strangulation of intestinal obstruction $\operatorname{cases}^{27}$. We are not concurring with the above observations.

We are more than $95 \%$ accurate in diagnosing strangulation/ischemia with regular clinical examinations and imageology. We feel the above reasons are responsible for the low mortality rate.

\section{CONCLUSIONS}

Intestinal obstruction is more common in females $56 \%$ verses $44 \%$. Tubo-ovarian masses and uterine adhesions are responsible for high incidence. If we exclude gynaecological causes, both sexes are nearly equally affected.

Adhesions and bands are a major cause of intestinal obstruction- $42.66 \%$. it is more common in $3^{\text {rd }} \& 4^{\text {th }}$ decades followed by $5^{\text {th }} \& 6^{\text {th }}$ decades. Anastomotic leak is more common in strangulated bowel \& septic shock patients. Mortality is more in anastomotic leak patients. Handsewn anastomosis is less costly, though time consuming; gives equally good results in emergency surgeries \& less favorable conditions. Latest suture materials like PGA (Vicryl), PDS, and Prolene are superior to chromic catgut.

Financial or Other Competing Interests: None.

\section{REFERENCES}

[1] Zinner MJ, WAshley S. Maingot's abdominal operations 12th edn. McGraw-Hill Education 2013: p. 585.

[2] Irvin TT. Abdominal pain: a surgical audit of 1190 emergency admissions. Br J Surg 1989;76 (11):1121-5.

[3] Zinner MJ, WAshley S. Maingot's abdominal operations 12th edn. McGraw-Hill Education 2013: p. 587.

[4] Zinner MJ, WAshley S. Maingot's abdominal operations $12^{\text {th }}$ edn. McGraw-Hill Education 2013: p. 588.

[5] Ashley SW. ACS surgery: principles and practices. Vol. 2. $7^{\text {th }}$ edn. Decker Intellectual Properties 2014: p. 793.

[6] Haribhakti S. Surgical gastroenterology. Vol. 2. $2^{\text {nd }}$ edn. Paras 2014: p. 567

[7] Williams NS, Bulstrode CJK. Bailey and love's short practice of surgery. 25th edn. Hodder Arnold 2008: p. 1188.

[8] Miller G, Boman J, Shrier I, et al. Natural history of patients with adhesive small bowel obstruction. Br J Surg 2000;87 (9):1240-7.

[9] Foster NM, McGory ML, Zingmond DS, et al. Small bowel obstruction: a population-based appraisal. J Am Coll Surg 2006;203 (2):170-6.

[10] Zinner MJ, WAshley S. Maingot's abdominal operations 12 th edn. McGraw-Hill Education 2013: p. 595.
[11] Pujari BD, Deodhare SG. Necrotizing enteritis. BR J Surg 1980;67 (4):254-6.

[12] Wig JD, Malik AK, Suri S, et al. Acute segmental enteritis. J Diarrhoeal Dis Res 1984;2 (1):37-40.

[13] Sahoots IG, Koffeman GI, Legemate DA, et al. Systemic review of survival after acute mesenteric ischemic according to disease aetiology. Br J Surg 2004; 91 (1):1727.

[14] Begos DG, Sandor A, Modlin IM. The diagnosis and management of adult intussusception. Am J Surg 1997;173 (2):88-94.

[15] Katariya RN, Sood S, Rao PG, et al. Stricture-plasty for tubercular strictures of the gastro-intestinal tract. Br J Surg 1977;64 (7):496-8.

[16] Gillespie IE. Intestinal anastomosis. Br Med J (Clin Res Ed) 1983;286 (6370):1002.

[17] Schrock TR, Deveney CW, Dunphy JE. Factors contributing to leakage of colonic anastomoses. Ann Surg 1973;177 (5):513-8.

[18] Singh KK, Aitken RJ. Outcome in patients with colorectal cancer managed by surgical trainees. Br J Surg 1999;86 (10):1332-6.

[19] Matthiessen P, Hallbook O, Rutegard J, et al. Defunctioning stoma reduces symptomatic anastomotic leakage after low anterior resection of the rectum for cancer: a randomized multicenter trial. Ann Surg 2007;246 (2):207-14

[20] Fielding LP, Stewart-Brown S, Blesovsky L, et al. Anastomotic integrity after operations for large - bowel cancer: a multicentre study. $\mathrm{Br}$ Med J 1980;281 (6237):411-4.

[21] Hesp FL, Hendriks T, Lubbers EJ. Wound healing in the intestinal wall. A comparison between experimental ileal and colonic anastomosis. Dis Colon Rectum 1984:27 (2):99-104.

[22] Burch JM, Franciose RJ, Moore EE, et al. Single-layer continuous versus two-layer interrupted intestinal anastomosis a prospective randomized trial. Ann Surg 2000;231 (6):832-7.

[23] Docherty JG, McGregor JR, Akyol AM, et al. Comparison of manually constructed and stapled anastomosis in colorectal surgery. Weest of Scotland and Highland Anastomosis Study Group. Ann Surg 1995;221 (2):17684.

[24] Ellozy SH, Harris MT, Bauer JJ, et al. Early postoperative small-bowel obstruction: a prospective evaluation in 242 consecutive abdominal operations. Dis Colon Rectum 2002;45(9):1214-7.

[25] Sosa J, Gardner B. Management of patients diagnosed as acute intestinal obstruction secondary to adhesions. Am Surg 1993;59 (2):125-8.

[26] Sajja SBS, Schein M. Early postoperative small bowel obstruction. Br J Surg 2004;91 (6):683-91.

[27] Sarr MG, Bulkley GB, Zuidema GD. Preoperative recognition of intestinal strangulation obstruction: prospective evaluation of diagnostic capability. Am J Surg 1983;145 (1):176-82. 